\title{
O ENSINO DE LÍNGUA INGLESA PARA CRIANÇAS VIA SEQUÊNCIA DIDATICA: UMA PROPOSTA METODOLÓGICA
}

\author{
Monique Susan Morara Lavisio (PPGEL/UEL - CAPES) \\ Hélida Santana
}

O uso de gêneros textuais no ensino de línguas vem sendo amplamente estudado por vários pesquisadores. No entanto, o ensino de língua inglesa para crianças ainda é um campo pouco explorado, necessitando de estudos que auxiliem na formação dos professores. Desta forma, este trabalho tem o intuito de apresentar uma proposta de ensino de inglês para crianças baseada no gênero textual história infantil. Para tanto, faz-se uso do dispositivo Sequência Didática, fundamentada no aporte teórico do Interacionismo Sociodiscursivo (BRONCKART 2003; DOLZ; NOVERRAZ; SCHNEUWLY, 2004; TONELLI, 2008; CRISTÓVAO, 2001). Esta concepção metodológica tem auxiliado e direcionado muitas práticas em sala de aula. Assim, objetiva-se apresentar uma Sequência Didática para o ensino-aprendizagem de Língua Inglesa para crianças, considerando o contexto dos anos iniciais do Ensino fundamental no ensino público do município de Londrina. Espera-se que este trabalho possa ampliar a discussão sobre as condições de um aprendizado significativo e contextualizado, possibilitando uma organização que permita sempre retomar e reforçar os conteúdos a partir das necessidades encontradas.

Palavras-chave: Sequência Didática, História Infantil, Ensino de inglês para crianças.

\section{INTRODUÇÃO}

È sabido que o ensino público de Língua Inglesa para crianças tem pouca representatividade nas propostas pedagógicas escolares. Contudo, em tempos atuais, há uma maior preocupação com esta vertente de ensino, o que tem acrescido na busca de implementação de projetos de Língua Inglesa para as séries inicias. O número de pesquisas voltadas à produção de material didático para o ensino de língua estrangeira tem avolumado e ampliado o campo de trabalho dos professores; no entanto, considerase que ainda exista um numero insuficiente de produções de materiais para suplantar a necessidade dos profissionais de língua estrangeira no cotidiano, principalmente no ensino para crianças.

Tomando por base a teoria dos estudos voltados ao ensino de línguas (CRISTOVÃO, TONELLI, 2005; DOLZ, SCHNEUWLY,) e dos gêneros textuais; sequencia didática (BRONCKART, 2003), pretende-se contribuir com o trabalho do professor apresentando uma proposta de sequencia didática com o livro "The Very Hungry Caterpillar" de Eric Carle como objeto de ensino, adotando o gênero história infantil como instrumento mediador no letramento escolar do alunado.

Acredita-se que a sequencia didática oferece situações de aprendizagem para o letramento do aluno construindo um aprendizado significativo por meio do gênero; permitindo ao individuo atuar nas diferentes esferas sociais agindo de modo ativo nas práticas

sociais. 


\section{SEMINÁRIO DE PESQUISA EM CIÊNCIAS HUMANAS - SEPECH \\ Humanidades, Estado e desafios didático-científicos \\ Londrina, 27 a 29 de julho de 2016}

Nessas condições, este artigo exibe, primeiramente, um breve aporte teórico da importância de contar histórias infantis como objeto de ensino para letrar o aluno permitindo-o atuar nas diferentes esferas. Além disso, tratar-se-á da questão do ensino de língua com gêneros textuais; logo após, apresenta-se uma proposta de ensino com gêneros via Sequencia didática; e por fim, as considerações finais deste projeto.

\section{O GÊNERO: HISTÓRIA INFANTIL NA LI}

As Histórias Infantis podem ser consideradas um eficiente gênero a ser utilizado como instrumento no ensino de inglês para crianças (TONELLI, 2008). Elas permitem que a criança viagem a lugares em que ela não pode estar. Ao ler uma história a criança incorpora os significados que a narrativa transmite envolvendo-se no contexto narrado; satisfazendo seus anseios; e enriquecendo o seu conhecimento e a constituição de sua infância.

As Histórias Infantis tem o poder de auxiliar os indivíduos no processo de desenvolvimento como na construção de valores e convivência. De acordo com TONELLI (2008, p.21)

As HI são o produto de ação de linguagem, materializado por um autor empírico, como uma forma particular de representação social desse agente. A formalização desse mundo discursivo (das histórias infantis) é efetivada por um conjunto de representações sociais, por meio do conhecimento do contexto histórico e do contexto de produção (contexto físico, social e subjetivo).

Pode-se afirmar que o liame de tais elementos narrativos pode oferecer ao aluno um aprendizado significativo e contextualizado. $\mathrm{O}$ ato de ouvir histórias permite ao indivíduo o despertar de uma formação leitora; esta prática articula o senso crítico do aluno e o seu modo de ler o mundo. Segundo Abramovich (2001, p. 16). "é importante para a formação de qualquer criança ouvir muitas, muitas histórias e escutá-las é o inicio da aprendizagem para ser leitor e ser leitor é ter um caminho de compreensão do mundo".

As pensar no trabalho com gêneros, pesquisas revelam que as HI são capazes de ir além das estruturas gramaticais, abrindo um leque para outros contextos a serem trabalhados com os alunos por meio das Histórias Infantis. A esse respeito Kato (1997, p.41) relata que "ao ouvir histórias, a criança vai construindo seu conhecimento da linguagem escrita, que não se limita ao conhecimento das marcas gráficas a produzir ou a interpretar, mas envolve gênero, estrutura textual, funções, formas e recursos linguísticos".

Diante do exposto, entende-se que o trabalho com gêneros é enriquecedor para a construção do seu conhecimento linguístico; e se bem articulado e utilizado para o ensino de língua inglesa para criança, ele pode ser um excelente fio condutor para o indivíduo adquirir um bom desempenho no aprendizado de uma segunda língua.

\section{O GÊNERO COMO SUPORTE PARA PRÁTICA}




\section{SEMINÁRIO DE PESQUISA EM CIÊNCIAS HUMANAS - SEPECH \\ Humanidades, Estado e desafios didático-científicos \\ Londrina, 27 a 29 de julho de 2016}

Os gêneros textuais/discursivos constituem-se de características heterogênea e relativamente estáveis (BAKHTIN, 2003), se alterando dentro de cada esfera. Por circularem em diferentes espaços, é necessário que o indivíduo se apodere desses inúmeros gêneros que o cerca para atuar nas diferentes esferas.

Acredita-se que o ensino por meio do gênero possa auxliar o individuo no seu processo de letramento escolar. É possivel dizer que, se o aluno absorver o ensinamento que a proposta com gênero aborda, ele provavelmente poderá enriquecer seu discurso, construindo sua identidade linguistica na língua estudada para atuar ativamente e compreender a língua nos diferentes espaços que ela circula.

Nesse sentido, ao relacionar o trabalho com gêneros ao letramento escolar, é necessário entender o processo de uma sequencia didática. As Seqüências Didáticas (SD) se embasam na perspectiva dos gêneros como objeto de ensino; "elas funcionam como encaminhamento metodológico de trabalho, sendo uma forma de criar condições para que os alunos sejam confrontados com diferentes práticas de linguagem historicamente construídas, oportunizando a sua reconstrução e a sua apropriação" (COSTA-HÜBES e BAUMGÄRTNER, 2007, p. 17).

Conforme a metodologia da SD o trabalho com gênero parte de uma produção inicial de leitura, escrita, ou fala, quando "o aluno estaria atendendo uma situação real de comunicação, em dada esfera social, revelando as representações que têm do gênero em questão" (DOLZ, NOVERRAZ e SCHNEUWLY, 2004, p.95-128).

Entende-se que na SD a produção inicial é o começo para a organização dos módulos, ao qual se trabalhará os possíveis percalços que poderão ocorrer, na intenção de emponderar os alunos, dando a eles instrumentos necessários para construírem um bom texto, seja ele oral ou escrito, do gênero escolhido, contemplando todas as suas características. A Sequência didática apresenta, como produção final, uma atividade de fechamento que contribuirá para que o aluno coloque em prática todo conhecimento adquirido no ensino do gênero estudado, onde só então ocorrerá a avaliação de todo o processo.

De acordo com Dolz, Noverraz, Schneuwly (2004) este seria um esquema de SD para o ensino com gêneros:

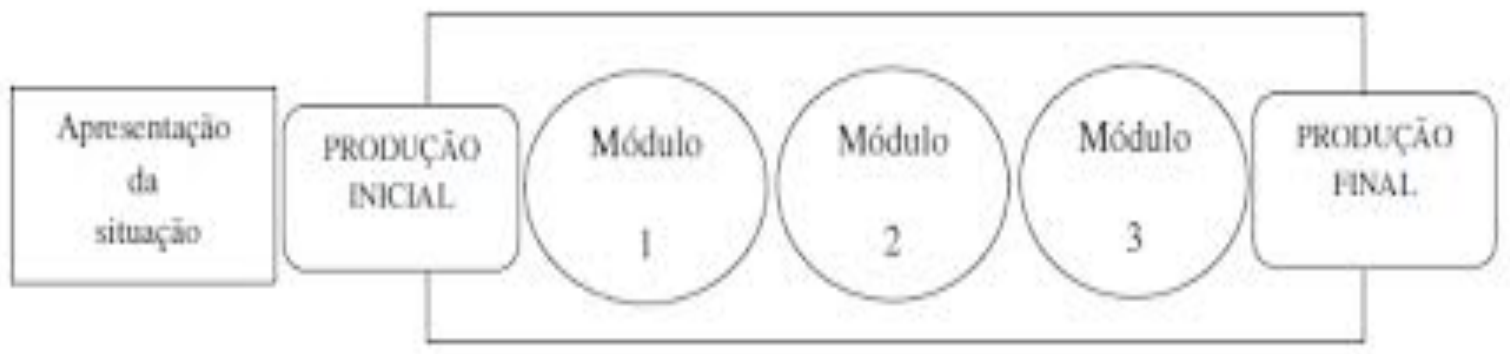

Figura 1 - Esquema de Sequencia didática

Fonte: Dolz, Noverraz e Schneuwly (2004, p. 97).

Este esquema distribui o ensino de gêneros em: Apresentação da situação de produção de um gênero, onde o professor compartilha com os alunos o projeto de ensino ao qual estarão envolvidos por um tempo, no qual se pode estudar um gênero 


\section{SEMINÁRIO DE PESQUISA EM CIÊNCIAS HUMANAS - SEPECH \\ Humanidades, Estado e desafios didático-científicos \\ Londrina, 27 a 29 de julho de 2016}

oral ou escrito; além das etapas que os alunos percorrerão para chegarem a uma produção final. Logo após, é realizada uma produção inicial, no qual o objetivo é captar o conhecimento prévio do aluno voltado ao gênero, e será por meio dela que o professor se programará para as futuras intervenções dos módulos. Mais adiante, iniciam-se os módulos intermediários, o qual será estudado os elementos que auxiliam na constituição do gênero, por meio de atividades que se destinarão à progressão do gênero, no caso, a história infantil é utilizada para contribuir no letramento do aluno e na produção de outro gênero. Por fim, será proposta uma atividade de produção final, o qual servirá de parâmetro para avaliar todo o processo de ensino do gênero. Lembrando que o professor proporá uma grade de elementos que auxiliem na organização da produção significativa do gênero.

Diante do exposto é relevante lembrar que todas essas etapas são necessárias para o estudo do gênero com o qual se pretende trabalhar, pois este esquema oferece o estudo por etapas captando toda a estrutura e características do gênero, avaliando formativamente a produção dos alunos.

\section{PROPOSTA METODOLÓGICA - SEQUENCIA DIDÁTICA}

Para dar início a essa proposta é interessante orientar que esta sequência didática foi estruturada para alunos de $4^{\circ}$ ano das series inicias. A elaboração dos módulos foi pensada na faixa etária dos alunos, tomando como base o gênero história infantil "The Very Hungry Caterpillar” de Eric Carle e os conteúdos estudados nesta série escolar.

\section{APRESENTAÇÃO DA SITUAÇÃO}

Inicia-se esta SD com a apresentação da situação que se baseará em contar aos alunos sobre os trabalhos que realizaremos inspirados na história do livro "The Very Hungry Caterpillar". O professor explana que serão explorados durante este projeto: a oralidade das crianças expressando e identificando seus alimentos preferidos; as marcas linguísticas "I like / I don't like", e as estruturas da língua com: "Do you like...? Yes, I do. / No, I don't."; trabalhando as habilidades do falar, ouvir e escrever, exprimindo as preferências pelos alimentos apresentados. Além de falar sobre comidas saudáveis e não saudáveis.

\section{PRODUÇÃO INICIAL}

Dar início com questionamentos sobre a metamorfose da borboleta apresentando um breve documentário sobre esse processo de transformação. Com isso o professor anuncia aos alunos que contará uma história fantasiosa sobre o fato da transformação de uma "Caterpillar" (lagarta). Ao contar em inglês a história "The Very Hungry Caterpillar" com o livro e o auxílio de "flashcards" coloridos, o mediador questiona sobre a história com os alunos para captar as percepções absorvidas da história, e pede para que eles oralmente relatem uma lista dos alimentos ingeridos pela lagarta ("Caterpillar"), seja ela em português, ou em inglês (caso já tenham internalizado o vocabulário), ao relatarem ela pergunta se a lagarta teve uma boa alimentação, se era 


\section{SEMINÁRIO DE PESQUISA EM CIÊNCIAS HUMANAS - SEPECH \\ Humanidades, Estado e desafios didático-científicos \\ Londrina, 27 a 29 de julho de 2016}

saudável ou não; no entanto este assunto será tratado com mais atenção, em outro módulo.

\section{Modulo 1 - Aprofundando-se no assunto}

Neste próximo módulo, o professor anuncia a aula questionando sobre o vídeo, (o documentário real de uma lagarta) e a história fantasiosa, destacando os alimentos que aparecem na história. À medida que os alunos relembram os alimentos, o professor retira a fruta (real, de plástico ou em figuras) de uma caixa e ensina em inglês o nome do alimento, pedindo que eles repitam em inglês, e passem o item alimentício para o colega, ao mesmo tempo em que repete seu nome em inglês.

$\mathrm{Na}$ aula seguinte, o professor inicia perguntando aos alunos quais foram os alimentos ingeridos pela "Caterpillar" e explica o que significa a pergunta : "Do you like Apple?" E as respostas: "Yes, I do/ No, I don't". Explicar como se exprime as preferências, sempre frisando (Yes, I do/ No, I don't), questionando e praticando as expressões com o professor e os colegas de sala. Logo após, convida-se a criança para vir à frente da sala e tirar uma "food" da caixa, tentando lembrar o nome em inglês (com o auxílio do professor), então o docente questiona se ela gosta ou não daquele alimento; ao responder o aluno se dirige a outra criança e, por sua vez, pergunta para se ela gosta: "Do you like...?" "Yes, I do." Ou "No, I don't." Com isso, o professor explica que a criança produzirá uma lista de alimentos, individualmente, no caderno, sob o título: "I like ... /I don't like ..."

No próximo encontro, inicia-se a aula perguntando sobre a lista, pedindo para que eles falem de um a dois itens da lista de comida que eles gostem e que eles não gostem, enfatizando a estrutura e o vocabulário ensinado "I like..., I don't like...". Em seguida, o professor apresenta um vídeo cantado, com as estruturas "Do you like...?" etc, cantando junto com as crianças e enfatizando as respostas com gestos: "Yes, I do / No, I don't."

Após a compreensão do vocabulário, e para encerrar este módulo, o professor apresenta um "game" às crianças "Run and Get", em que elas correm e pegam o alimento mencionado pela professora. Ganha quem trouxer o alimento certo e primeiro. O nome de cada time é um nome de um item alimentício, escolhido pelo grupo.

Desta forma, passamos para próxima fase deste projeto.

\section{Modulo 2 - "Junk Food / Healthy Food" - classificando alimentos}

O professor introduzirá o significado das expressões "Junk Food and Healthy Food", explicando seu significado e mostrando alguns alimentos, questionando: "Is it Junk or Healthy food?".

Baseado na lista dos alimentos preferidos pelo gosto individual da criança e produzida em aulas anteriores, elas classificarão os alimentos formando uma nova lista individual nas categorias "Junk" ou "Healthy". Concluída a classificação, o professor desenhará duas colunas no quadro, com os títulos "junk" e "healthy" e pedirá a cada aluno que escolha da sua lista individual um item para ser escrito nestas categorias. Ao mesmo tempo em que o professor escreve, ele também questionará toda a classe caso haja alguma dúvida sobre a categoria daquele item em questão. O docente explanará as crianças que as nossas dúvidas serão melhor esclarecidas pela nutricionista da escola que irá nos visitar pra falar sobre este assunto na aula posterior. 


\section{SEMINÁRIO DE PESQUISA EM CIÊNCIAS HUMANAS - SEPECH \\ Humanidades, Estado e desafios didático-científicos \\ Londrina, 27 a 29 de julho de 2016}

Chegado o próximo encontro, as crianças receberão a nutricionista da escola, que responderá as perguntas que ainda não ficaram esclarecidas sobre o que vem a ser, de fato, um item alimentício classificado como "Besteira" ou "Porcaria" (como dizem as mães) ou como uma comida saudável. Por exemplo: Bolo é ou não é "Junk food". E a pizza?.

Em outro momento, eles refletirão sobre a frequência com que comem comidas não saudáveis e saudáveis, e quantos dias da semana têm esta prática. A partir daí, será introduzido os dias da semana na língua inglesa. Como exercício, eles classificarão os alimentos não saudáveis (junk food) de acordo com o dia da semana, explicando o que de "junk food" comem em cada dia.

Internalizado este assunto, poder-se-á seguir para a próxima etapa, que se concentrará na produção de um cardápio individual.

\section{Módulo 3 - Produção de um cardápio individual}

Baseados na instrução da nutricionista, as crianças então produzirão, em casa, um cardápio individual, utilizando cada dia da semana para organizá-lo. O docente relembrará este assunto, com a história contada, relembrando as crianças do cardápio da "Caterpillar", que cada dia da semana ela ingeria um alimento diferente, frisando o resultado daquele cardápio na vida dela. Por meio da história, poderá ser recordado que, o que comemos interfere não só na nossa aparência corporal, mas no nosso humor e até no nosso rendimento escolar, ou seja, na nossa disposição pra estudar, realizar atividades, e até pra brincar; deixando assim que reflitam e decidam seus cardápios personalizados. As crianças entregarão seus cardápios para o professor e a partir de então o professor o revisará explicando sobre as características e os itens inclusos num cardápio, como: a lista de alimentos, as refeições diárias e os dias da semana; os alunos colocarão seus cardápios nos moldes explanados pela professora e eles poderão reestruturá-lo.

Nesta reestruturação, eles voltarão para casa com os cardápios reorganizados e explicarão aos familiares sobre a possível prática do cardápio em seu cotidiano, ao retornarem a sala de aula o professor questiona se os alunos estão vivenciando e seguindo seus próprios cardápios. De acordo com esta sondagem, será proposto, neste próximo módulo, a produção de um cardápio coletivo.

\section{Produção Final - Produção de um Cardápio Coletivo}

Acreditando que esteja internalizado o assunto de "junk and healthy food", os alunos, em sala, produzirão um cardápio coletivo que será fixado no refeitório da escola para que outras crianças possam seguir a mesma restrição alimentar. Após as orientações da nutricionista e os assuntos discutidos em sala, acredita-se que eles tenham a propriedade de produzirem um cardápio para os colegas de escola. $\mathrm{O}$ cardápio apresentará uma linguagem de fácil compreensão, com palavras em inglês, figuras das mesmas, e os dias da semana, inclusive dias de sábado e domingo. Ao lado do cardápio será atribuída uma breve informação sobre o projeto aplicado.

Entende-se que se a criança tem um incentivo e um público para produzir um texto, e ao ver que este texto circula na esfera de sua vivência, ela certamente se empenhará em sua produção, o que resultará na atribuição de sentido para a circulação de seu texto e não meramente para a leitura do docente em sala. 


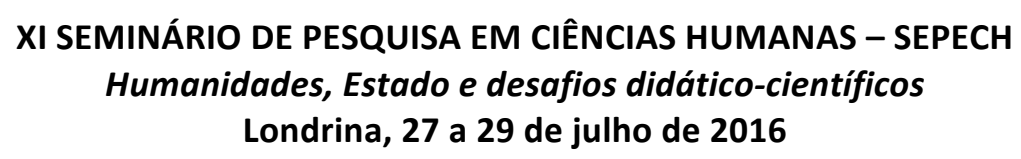

\section{CONSIDERAÇÕES FINAIS}

A intenção dessa proposta foi de contribuir para a formação do professor de línguas, principalmente, aos que dirigem o ensino da língua inglesa a crianças. Não se aplica aqui a pretensão de ensinar o gênero História Infantil, mas considerá-lo como um instrumento de ensino; devido à noção de pensar no ensino de língua estrangeira para crianças, como um estudo voltado somente ao léxico, acreditando que devido a idade e a não convivência com a língua os alunos sintam a dificuldade de aprender a língua.

Verificou-se que com o auxilio do gênero história infantil, o ensino da língua se torna mais significativo, ampliando as possibilidades de associar o contexto do aluno com a língua estudada aplicando sentido para ele ao aprender uma segunda língua.

A sequência didática proporciona subsídios que auxiliam o individuo em seu processo de letramento na língua. Ao se apropriar do conteúdo explorado nessa proposta, ele supostamente conseguirá atuar nas esferas que necessitem da compreensão do gênero proposto na sequencia, contribuindo para sua formação como cidadão crítico.

\section{REFERÊNCIAS}

ABRAMOVICH, Fanny. Literatura infantil: gostosuras e bobices. São Paulo: Scipione, 1991.

BRONKART, Jean-Paul. Atividade de Linguagem, textos e discursos. São Paulo: Educ, 2003.

COSTA-HÜBES, T. da C. O processo de formação continuada dos professores do Oeste do Paraná: um resgate histórico-reflexivo da formação em língua portuguesa. Londrina, PR: UEL, 2008 (Tese do doutorado em Estudos da Linguagem).

CRISTOVÃO, V. L. L. Gêneros e ensino de leitura em LE: modelos didáticos de gêneros na construção e avaliação de material didático. 2001. Tese (Doutorado em Linguística Aplicada e Estudos da Linguagem) - Pontifícia Universidade Católica de São Paulo, São Paulo: PUC-SP, 2001.

DOLZ, J.; NOVERRAZ, M.; SCHNEUWLY, B. Seqüências didáticas para o oral e a escrita: apresentação de um procedimento. In: DOLZ, J.; SCHNEUWLY, B. Gêneros orais e escritos na escola. [Tradução e organização: Roxane Rojo e Glaís Sales Cordeiro]. Campinas, SP: Mercado de Letras, 2004.

DOLZ, J.; SCHNEUWLY, B. Gêneros e progressão em expressão oral e escrita: elementos para reflexões sobre uma experiência suíça (francófona). In: SCHNEUWLY. B; DOLZ, J. Gêneros Orais e Escritos na Escola. Tradução e Organização de Roxane Rojo e Glaís Sales Cordeiro Campinas: Mercado de Letras, 2004. 


\section{SEMINÁRIO DE PESQUISA EM CIÊNCIAS HUMANAS - SEPECH \\ Humanidades, Estado e desafios didático-científicos \\ Londrina, 27 a 29 de julho de 2016}

KLEIMAN, A. O conceito de Letramento e suas implicações para a alfabetização. Projeto temático letramento do professor. Fev, 2007. Disponível em < www.letramento.iel.unicamp.br> acesso em 20/04/2016.

SUZUMURA, D. PADUA, L; TONELLI, J. A contribuição da sequencia didática para o desenvolvimento linguístico de crianças aprendizes de inglês como língua adicional.

Disponível

em

$<$ http://www.uel.br/eventos/semanaeducacao/pages/arquivos/ANAIS/ARTIGO/SABER

ES\%20E\%20PRATICAS/A\%20CONTRIBUICAO\%20DA\%20SEQUENCIA\%20DID

ATICA \%20PARA\%20O\%20DESENVOLVIMENTO\%20LINGUISTICO $\% 20$ DE $\% 20$

CRIANCAS\%20APRENDIZES\%20DE\%20INGLES\%20COMO\%20LINGUA\%20AD

ICIONAL.pdf $>$ Acesso em 20 de abril de 2016.

TONNELI, J. O uso de histórias infantis no ensino de inglês para crianças: analisando o gênero textual história infantil sob a perspectiva do interacionismo sóciodiscursivo. Rev Acta Sci. Lang. Cult. Maringá, v. 30, n. 1, p. 19-27, 2008. Disponível em

$<$ http://periodicos.uem.br/ojs/index.php/ActaSciLangCult/article/viewFile/4054/2895> Acesso em 10/05/2016. 